Kansas State University Libraries

New Prairie Press

\title{
GENOTYPE X WEATHER INTERACTIONS IN GRAIN YIELDS OF WHEAT
}

Arlin M. Feyerherm

Rollin G. Sears

Gary M. Paulsen

Follow this and additional works at: https://newprairiepress.org/agstatconference

Part of the Agriculture Commons, and the Applied Statistics Commons

\section{(c) (1) $\Theta$}

This work is licensed under a Creative Commons Attribution-Noncommercial-No Derivative Works 4.0 License.

\section{Recommended Citation}

Feyerherm, Arlin M.; Sears, Rollin G.; and Paulsen, Gary M. (1990). "GENOTYPE X WEATHER INTERACTIONS IN GRAIN YIELDS OF WHEAT," Conference on Applied Statistics in Agriculture. https://doi.org/10.4148/2475-7772.1433

This is brought to you for free and open access by the Conferences at New Prairie Press. It has been accepted for inclusion in Conference on Applied Statistics in Agriculture by an authorized administrator of New Prairie Press. For more information, please contact cads@k-state.edu. 


\title{
GENOTYPE X WEATHER INTERACTIONS IN GRAIN YIELDS OF WHEAT
}

\author{
Arlin M. Feyerherm \\ Department of Statistics
}

\author{
Rollin G. Sears \\ Department of Agronomy \\ Kansas State University \\ Manhattan, KS 66506
}

\author{
Gary M. Paulsen \\ Department of Agronomy
}

\section{ABSTRACT}

The purpose of this paper is to demonstrate the advantage of using weather elements as covariates in studying yield differentials between varieties of wheat over different climatological regions. Using regression methods, the dependence of varietal yield differences on weather elements was demonstrated with a relatively small sample consisting of yield and weather data over a 3-year period from nine locations in Kansas. For each location, the sample-derived regression equation was used to calculate predicted yield differentials and $95 \%$ confidence intervals for the mean (CLM) for each year from 1950 through 1989. The proportion of CLMs that covered positive (or negative) values only was considered an important statistic. For each location, it estimated the proportion of years when the average yield of one variety was quite certain to exceed that of another.

The procedure was applied to the problem of choosing new varieties for release to wheat growers. Results showed that a new variety, Karl, could be expected to outyield a popular variety, Newton, in more than $50 \%$ of the years in climates with mean annual precipitation exceeding 28 inches. Further, the mean yield of Karl could be expected to exceed that of another popular variety, Arkan, in over 50\% of the years at almost all locations across the state.
\end{abstract}

KEYWORDS: wheat varieties, weather, interactions

\section{INTRODUCTION}

Knowledge of genotype $\mathrm{x}$ environment interaction effects is important in the selection and future development of wheat varieties. Breeding and selection of new varieties that uniformly outyield popular varieties across a wide range of environments is important but extremely difficult to attain. Differential environments are generated by climate, disease, soil, and other nongenetic factors, which work together in a complex way to produce differential grain yields.

Various statistical methods have been proposed to detect and measure genotype $\mathrm{x}$ environment effects (Liu, 1987). In application, the usual sources of data are varietal performance tests replicated over years and locations. Commonly used methods are (1) comparisons of simple means at different locations; (2) general linear models to relate yields to genotypes, locations, years, and their interactions; and (3) regression of individual yields for a variety on an environmental index, often taken to be the mean yield of all varieties in a given location-year (Yates and Cochran, 1938; Eberhart and Russell, 1966). Rather than use the mean yield as an environmental index, others have used weather factors (temperature and precipitations) during a given season (Saeed and Francis, 1984; Nor and Cady, 1979). 
In this paper, we applied the above three methods but used yield differentials to compare the yielding ability of a new variety, Karl, with two varieties, Newton and Arkan, which have been popular with producers in Kansas in the 1980s. In the regression approach, we used functions of temperature and precipitation for different periods of the season as an environmental index. Insight into choice of weather variables was gained from previous work (Feyerherm and Paulsen, 1990).

\section{MATERIAIS AND METHODS}

Plot yields for Karl, Arkan, and Newton and daily weather data for five seasons were available at some or all of nine locations across Kansas (Table 1). For 1985 and 1986, yield data were taken from nurseries for testing advanced lines before release of varieties; for 1987 through 1989, data were from performance trials among elite lines plus a few lines in their final stages of testing before release as new varieties. The two response variables of interest were differences in yield between Karl and Arkan (KARL-ARKAN) and Karl and Newton (KARL-NEWTON).

Three statistical procedures were compared for their ability to detect and assess whether the means for (KARL-ARKAN) and (KARL-NEWTON) were significantly different from zero over all or some of the climates of Kansas. The procedures were: (1) using simple means, (2) using a general linear model (GLM) with locations and years as dependent variables, and (3) regressing (KARL-ARKAN) and (KARL-NEWTON) on weather variables that summarized conditions over part or all of the growing season for winter wheat. Weather variables were defined by: (1) type of weather element (precipitation or temperature) and (2) the period of the season covered based on a crop calendar (Figure 1) for winter wheat.

Candidate weather variables for inclusion in regression equations for (KARL-ARKAN) and (KARL-NEWTON) are shown in Figure 2. The PROC STEPWISE procedure in SAS User's Guide: Statistics (SAS Institute Inc., 1985) was used for variable selection.

With long-term historical weather data, the third procedure has the advantage that it can be used to study yield differentials ( $\hat{D}$ s) for locations and years that are not included in the development set. Such studies were done for nine locations in Kansas. From 40 years (19501989) of data per location, means of $\hat{D}$ s over years and a $95 \%$ Confidence Intervals (CLM) for each year's estimate were used to describe the behavior of (KARL-ARKAN) and (KARLNEWTON) over time. Of particular interest was the percentage of years when CLMs at a given location included only positive values. In such years, one could conclude with $95 \%$ confidence that the mean yield of Karl would exceed that of a "standard" variety (Arkan or Newton).

\section{RESULTS}

In Kansas, varieties are considered for public release only after they have been grown in nurseries for at least 3 years. We compared Karl with Newton and Karl with Arkan after successive periods of 3 (1985-1987), 4 (1985-1988), and 5 vears (1985-1989) of testing.

The results of using simple means over all location-years across the state when both members of a pair were grown in a test are shown in Table 2. For 1985-87, Karl appeared to have an advantage over Newton, but that advantage disappeared as the fourth and fifth years were added to the data set. On the other hand, the advantage of Karl over Arkan increased and became statistically significant when 1988 and 1989 data were added. 
To test whether variety $\mathrm{x}$ environment interactions might be masking the magnitude of yield differences, we used PROC GLM in SAS to look for location and year effects on yield differences. Results are shown in Table 3. Only the test results for (KARL-NEWTON) during the '85-' 87 seasons showed a significant $(P<.01)$ location effect. This effect was traced to superior yields of Karl at Belleville and Manhattan (Table 4). Thus, the technique of using location and years as explanatory variables for yield differences was inadequate to detect whether Karl would outyield Newton and/or Arkan in the long-run, at least in certain locations and/or years.

The results of applying a third statistical procedure (regressing yield differences on weather variables) are shown in Table 5. Clearly, certain weather elements affect yield differences, so that a weather component of a genotype $\mathrm{x}$ environment interaction effect exists. This approach identifies physical factors (weather elements) as components of this interaction and estimates their effects on yield differences. For (KARL-NEWTON), precipitation from the beginning of winter dormancy through the hard dough stage (PR_WD) explained a significant amount of variation. Further, there was only minor change in the coefficients of PR_WD as the fourth and fifth years of data were added. For (KARLARKAN), the variable PR_PW (precipitation from planting to dormancy) replaced TN_SJ (minimum temperature from spring green-up to jointing) in the equation when the fifth year of data was added but PR_HD (precipitation from head to hard dough stage) was retained. Thus, in locations/years when PR_HD exceeds 2.8 inches, Karl had an extra yield advantage over Arkan beyond that estimate $\bar{d}$ by the leading constant term in an equation; however, it lost some advantage when TN_SJ exceeded $32.1^{\circ} \mathrm{F}$ or PR_PW exceeded 3.2 inches.

This approach assumed that an added inch of precipitation or an added degree of temperature had the same effect whether it happened between two different years or two locations. Some credibility to this assumption is illustrated in Figure 3, where yield differences between Karl and Newton were plotted against (PR_WD-11.8). The numbers identify a data point for a given location (see Table 1). Thus, the 4 s identify data points for Hays for the 5 years. Visually, there was no clear evidence against a common regression for all locations. Statistically, the (PR_WD) $x$ location effect was not significant in a general linear model relating yield differentials to locations and PR_WD. Likewise, the (PR_WD) $x$ years effect was not significant when relating yield differentials to years and the covariate, PR_WD.

The regression equations plus availability of daily weather data from 1950 through 1989 at all nine locations permitted yearly estimates of yield potential of Karl relative to Newton and Arkan at each location over the past 40 years. From Figure 3, predicted values of KARLNEWTON can be visualized moving up and down the regression line as values of PR_WD vary from year to year. One statistic of interest would be means of such predicted values, over the 40 years by location, which are shown in Table 6 . The results clarify yield potential of Karl relative to Newton and Arkan by location (compare with Table 4). Karl has no advantage over Newton (and may have a disadvantage) in the dry western locations but shows a distinct advantage in humid climates. The advantage of Karl over Arkan appears to be statewide. The advantage of Karl over Newton in high rainfall areas (roughly, the eastern half of Kansas) and of Karl over Arkan statewide is exhibited in another form in Table 7. Using the regression equation developed from 1985-89 data, the yearly values of CLMs provided $95 \%$ confidence that the mean yield of KARL-ARKAN would be greater than zero in over $50 \%$ of the years at every location. The same statement can be made about KARLNEWTON in locations in eastern Kansas. 


\section{SUMMARY AND CONCLUSIONS}

Selection of varieties of wheat from a wheat breeding program for ultimate release to growers is a painstaking task that includes testing under multiple environmental field conditions. Variation in environmental conditions is evaluated by replicating tests over locations and years. In this paper, we compared three different statistical procedures for their ability to detect whether a new variety, Karl, would outyield two varieties, Newton and Arkan, which were popular with Kansas producers in the 1980 s.

Meteorological elements (precipitation/temperature) were informative covariates when studying varietal yield differences and could be used to delineate the yield advantage of Karl in specified climatological regions. Conclusions after 5 years of testing did not differ appreciably from those after only three years. Our procedure adds another dimension to the selection process by evaluating yield response over a broad range of climates and gives added assurances about the direction of yield differentials in years that are not included in the test data.

\section{REFERENCES}

1. Eberhart, S.A. and W.A. Russell. 1966. Stability parameters for comparing varieties. Crop Sci. 6:357-360.

2, Feyerherm, A.M. and G.M. Paulsen. 1990. Model building to measure impact of weather on crop yields. p. 137-145. In G.A. Milliken and J. Schwenke (ed.) Applied Statistics in Agriculture. Proc. KSU Conference on Applied Statistics in Agriculture. Kansas State University, Manhattan. 30 April-2 May, 1989.

3. Liu, B.H. 1987. Genotype $x$ environment interaction and application. M.S. thesis. Kansas State University, Manhattan.

4. Nor, K.M. and F.B. Cady. 1979. Methodology for identifying wide adaptability in crops. Agron. J. 71: 556-559.

5. Saeed, M. and C.A. Francis. 1984. Association of weather variables with genotype $\mathrm{x}$ environment interactions in grain sorghum. Crop Sci. 24:13-16.

6. SAS Institute Inc. 1985. SAS User's Guide: Statistics, Version 5 Edition. Cary, NC: SAS Institute Inc., $956 \mathrm{pp}$.

7. Yates, F. and W.G. Cochran. 1938. The analysis of groups of experiments. J. Agric. Sci. 28:556-580. 
Figure 1. Crop Calendar for winter wheat.

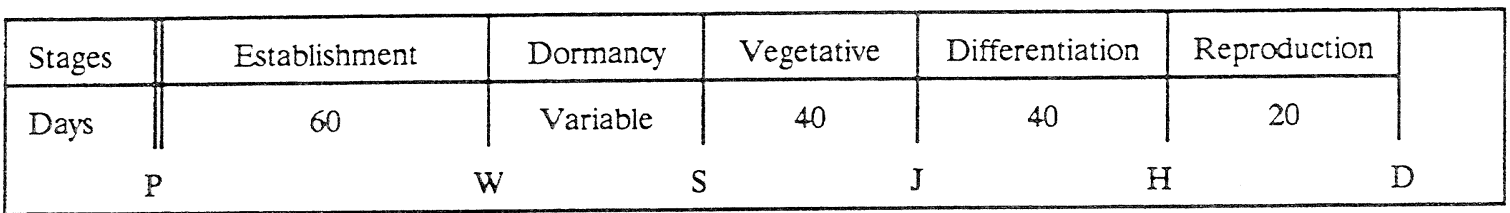

$\mathrm{P}$ - average planting date $=154.3+2.16\left(\mathrm{TA} \_\mathrm{SN}\right)$,

$\mathrm{W}$ - average date begin winter dormancy $=\mathrm{P}+60$,

$\mathrm{S}$ - average date begin spring green-up $=\mathrm{H}-80$,

$\mathrm{J}$ - average jointing date $=\mathrm{H}-40$,

$\mathrm{H}$ - average heading date $=253.8-2.06$ (TA_MM),

$\mathrm{D}$ - average date of hard dough $=\mathrm{H}+20$

where P, W, ..., D are in Julian days and TA_SN and TA_MM are 30-year average daily temperatures over the months of September through November and March through May, respectively, at a given location.

Figure 2. Candidate weather variables ${ }^{\dagger}$ for inclusion in regression equations for yield differentials.

\begin{tabular}{llllll|}
\hline TX_PW & PR_PW & PR_PS & PR_PJ & PR_PH & PR_PD \\
TN_WS & & PR_WS & PR_WJ & PR_WH & PR_WD \\
TN_SJ & & & PR_SJ & PR_SH & PR_SD \\
TN_JH & & & & PR_JH & PR_JD \\
TN_HD & & & & & PR_HD \\
\hline
\end{tabular}

TTX and TN are average daily maximum and minimum temperatures; respectively; and $\mathrm{PR}=$ total precipitation for the portion of the crop calendar (Figure 1) embraced by the two letters following the underline (e.g., PR_WD = precipitation from $W$ to $D)$. 
Figure 3. Differential yields (KARL - NEWTON) vs. precipitation (PR_WD - 11.8) from beginning of dormancy through dough stage for 1985-1989. Numbers represent points and identify locations (Table 1).

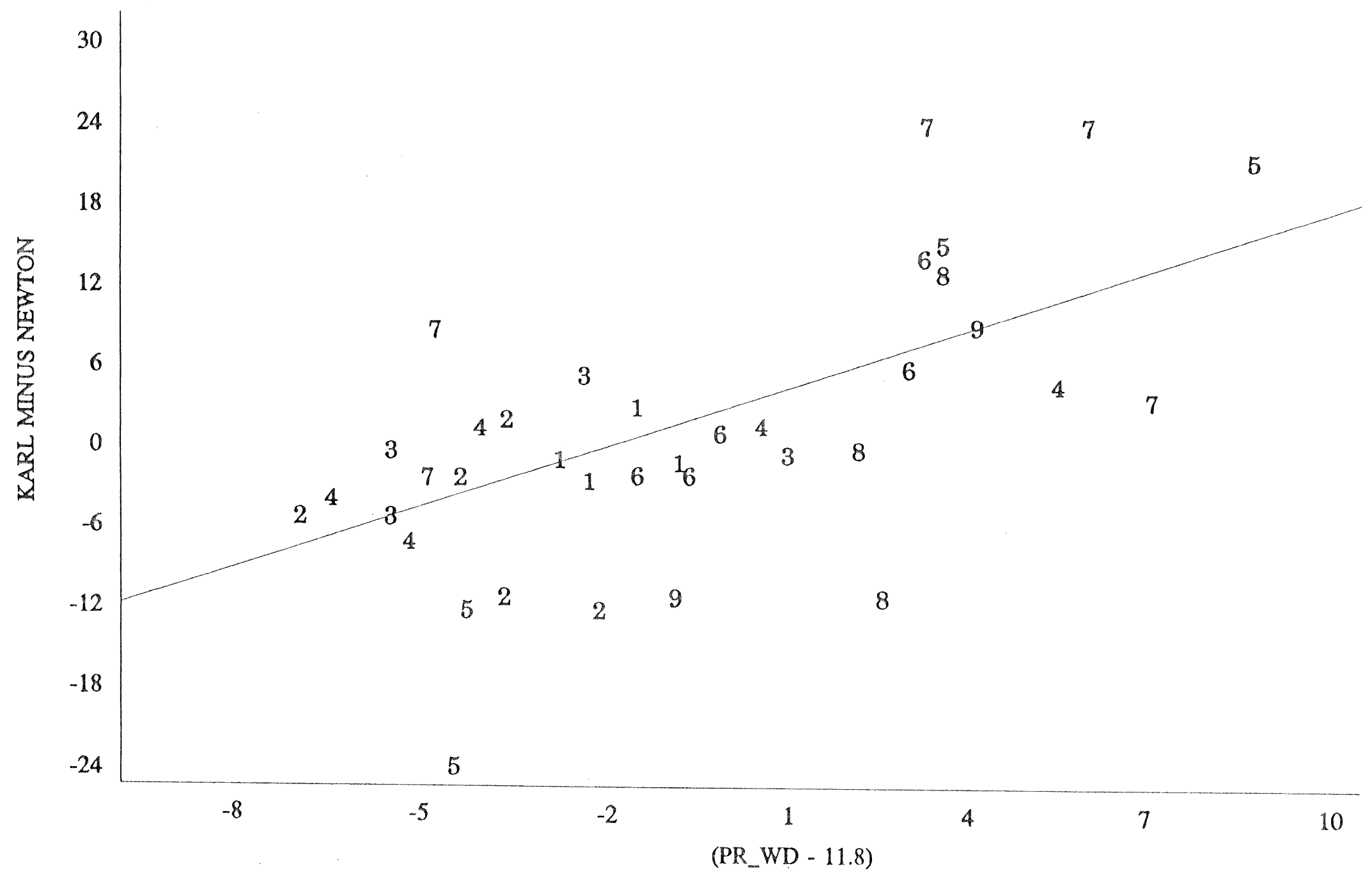


Table 1. Average annual precipitation (AAPR) at nine Kansas locations.

\begin{tabular}{cllc}
\hline No. & Location & \multicolumn{1}{c}{ Region } & AAPR (inches) \\
\hline 1 & Tribune & West Central & 16.8 \\
2 & Colby & Northwest & 18.6 \\
3 & Garden City & Southwest & 18.8 \\
4 & Hays & Central & 23.0 \\
5 & Belleville & North Central & 28.1 \\
6 & Hutchinson & South Central & 29.0 \\
7 & Manhattan & Northeast & 31.7 \\
8 & Ottawa & East Central & 37.2 \\
9 & Parsons & Southeast & 42.3 \\
\hline
\end{tabular}

Table 2. Simple means $(\bar{D})$ and standard errors of $\bar{D}(\operatorname{SE}(\bar{D}))$. Units are bushels/acre.

\begin{tabular}{|c|c|c|c|c|c|c|}
\hline \multirow[b]{2}{*}{ Years } & \multicolumn{3}{|c|}{ Karl minus Newton } & \multicolumn{3}{|c|}{ Karl minus Arkan } \\
\hline & $\underline{N}$ & $\underline{\mathrm{D}}$ & $\underline{\operatorname{SE}(\bar{D})}$ & $\underline{N}$ & $\overline{\mathrm{D}}$ & $\mathrm{SE}(\overline{\mathrm{D}})$ \\
\hline$\overline{85-' 87}$ & 20 & 5.8 & 2.5 & $\overline{20}$ & 2.7 & 1.6 \\
\hline '85-'88 & 29 & 2.6 & 2.2 & 29 & 2.3 & 1.2 \\
\hline '85-'89 & 37 & 2.3 & 1.8 & 36 & 2.9 & 1.1 \\
\hline
\end{tabular}

Table 3. Probabilities of greater F-values when testing null hypothesis about location and year effects in a general linear model for yield differences.

\begin{tabular}{cccccc}
\hline & \multicolumn{2}{c}{ Karl minus Newton } & & \multicolumn{2}{c}{ Karl minus Arkan } \\
\cline { 2 - 3 } \cline { 5 - 6 } Sample & Location & $\frac{\text { Years }}{\text { '85-'87 }}$ & & Location & $\frac{\text { Years }}{0.63}$ \\
'85-'88 & 0.01 & 0.82 & & 0.63 & 0.46 \\
'85-'89 & 0.46 & 0.14 & & 0.90 & 0.34 \\
\hline
\end{tabular}


Table 4. Least squares means for yield differences. Entries in bushels per acre.

\begin{tabular}{|c|c|c|c|c|c|c|}
\hline \multirow[b]{2}{*}{ Locations } & \multicolumn{3}{|c|}{ Karl minus Newton } & \multicolumn{3}{|c|}{ Karl minus Arkan } \\
\hline & '85-'87 & '85-'88 & '85-'89 & '85-'87 & '85-'88 & '85-'89 \\
\hline Tribune & -6 & -6 & -4 & 1 & 2 & 2 \\
\hline Colby & -1 & 0 & -1 & 0 & 2 & 3 \\
\hline Garden City & 4 & 2 & 2 & 3 & 4 & 5 \\
\hline Hays & 4 & 1 & 0 & 5 & 4 & 4 \\
\hline Belleville & $23^{*}$ & 7 & 3 & 10 & 6 & 7 \\
\hline Hutchison & 8 & 6 & 4 & 2 & 1 & 1 \\
\hline Manhattan & $19^{*}$ & $14^{*}$ & $13^{*}$ & 4 & 3 & 3 \\
\hline Ottawa & & 1 & 1 & & -5 & -5 \\
\hline Parsons & -7 & 5 & 10 & -8 & -2 & 2 \\
\hline
\end{tabular}

'Significantly different from zero at the $\mathrm{P}=0.05$ level.

Table 5. Regression equations ${ }^{\dagger}$ for different sample periods. Yields ( $\hat{D} s$ ) in bushels per acre, precipitation (PR) in inches, temperatures (TN) in ${ }^{\circ} \mathrm{F}$.

\begin{tabular}{|c|c|c|c|c|}
\hline Sample & $\mathrm{N}$ & Regression Equations & $\mathrm{R}^{2}$ & RMSE \\
\hline & & $\underline{\hat{D}}=$ KARL - NEWTON & & \\
\hline '85-'87 & 20 & $\hat{\mathrm{D}}=5.3+1.9\left(\mathrm{PR} \_\mathrm{WD}-11.8\right)$ & 0.53 & 8.0 \\
\hline '85-'88 & 29 & $\hat{\mathrm{D}}=3.4+2.0\left(\mathrm{PR} \_\mathrm{WD}-11.8\right)$ & 0.50 & 8.4 \\
\hline '85-'89 & 37 & $\begin{array}{l}\hat{\mathrm{D}}=3.6+1.8\left(\mathrm{PR} \_\mathrm{WD}-11.8\right) \\
\hat{\mathrm{D}}=\mathrm{KARL}-\mathrm{ARKAN}\end{array}$ & 0.45 & 8.2 \\
\hline '85-'87 & 20 & $\hat{\mathrm{D}}=7.9-0.9\left(\mathrm{TN} \_\mathrm{SJ}-32.1\right)+4.5\left(\mathrm{PR} \_\mathrm{HD}-2.8\right)$ & 0.37 & 7.9 \\
\hline '85-'88 & 29 & $\hat{\mathrm{D}}=6.0-0.6\left(\mathrm{TN} \_\mathrm{SJ}-32.1\right)+3.4\left(\mathrm{PR} \_\mathrm{HD}-2.8\right)$ & 0.33 & 5.6 \\
\hline '85-'89 & 36 & $\hat{\mathrm{D}}=4.2-0.7($ PR_PW -3.2$)+2.0\left(\mathrm{PR} \_\right.$HD -2.8$)$ & 0.30 & 5.5 \\
\hline
\end{tabular}

The constants inside parentheses $(11.8,32.1,3.2$, and 2.8$)$ are means over 360 locations-years ( 9 locations $\mathrm{x} 40$ years) for the respective variables. 
Table 6. Comparison of means of calculated D̂s (Table 5) for 1950-1989 using equations for '85-'87 and '85-'89. Entries are bushels per acre.

\begin{tabular}{|c|c|c|c|c|}
\hline \multirow[b]{2}{*}{ Location } & \multicolumn{2}{|c|}{$\hat{\mathrm{D}}=\mathrm{KARL}-\mathrm{NEWTON}$} & \multicolumn{2}{|c|}{$\hat{\mathrm{D}}=\mathrm{KARL}-\mathrm{ARKAN}$} \\
\hline & '85-'87 & '85-'89 & '85-'87 & '85-'89 \\
\hline Tribune & -3 & -5 & 6 & 4 \\
\hline Colby & 1 & -1 & 8 & 4 \\
\hline Garden City & -1 & -3 & 7 & 4 \\
\hline Hays & 2 & 0 & 7 & 4 \\
\hline Belleville & 8 & 6 & 8 & 5 \\
\hline Hutchison & 6 & 4 & 7 & 4 \\
\hline Manhattan & 9 & 8 & 10 & 5 \\
\hline Ottawa & 13 & 11 & 9 & 4 \\
\hline Parsons & 14 & 11 & 8 & 3 \\
\hline
\end{tabular}

Table 7. Percent of $95 \%$ confidence intervals of means (CLMs) with lower limit greater than zero $(\mathrm{N}=40)$.

\begin{tabular}{|c|c|c|c|c|}
\hline & \multicolumn{2}{|c|}{$\hat{\mathrm{D}}=\mathrm{KARL}-\mathrm{NEWTON}$} & \multicolumn{2}{|c|}{$\hat{\mathrm{D}}=\mathrm{KARL}-\mathrm{ARKAN}$} \\
\hline Location & '85-'87 & '85-'89 & '85-'87 & '85-'89 \\
\hline Tribune & 12 & 12 & $\overline{47}$ & 52 \\
\hline Colby & 32 & 22 & 55 & 60 \\
\hline Garden City & 22 & 22 & 52 & 58 \\
\hline Hays & 35 & 32 & 50 & 58 \\
\hline Belleville & 75 & 73 & 72 & 68 \\
\hline Hutchison & 60 & 55 & 65 & 73 \\
\hline Manhattan & 78 & 75 & 65 & 65 \\
\hline Ottawa & 95 & 92 & 65 & 65 \\
\hline Parsons & 92 & 90 & 68 & 52 \\
\hline
\end{tabular}

